\title{
A sensory- and consumer-based approach to optimize cheese enrichment with grape skin powders
}

\author{
L. Torri, ${ }^{\star 1}$ M. Piochi, ${ }^{\dagger} \dagger$ R. Marchiani, $\ddagger$ G. Zeppa, $\ddagger$ C. Dinnella, $†$ and E. Monteleone† \\ *University of Gastronomic Sciences, Piazza Vittorio Emanuele 9, 12060 Bra, Italy \\ †Department of Agricultural, Food and Forestry System Management, University of Florence, via Donizetti 6, 51144 Firenze, Italy \\ łUniversità di Torino, Dipartimento di Scienze Agrarie, Forestali e Alimentari, Via Leonardo da Vinci 44, 10095, Grugliasco, Torino, Italy
}

\begin{abstract}
The present study aimed to present a sensory- and consumer-based approach to optimize cheese enrichment with grape skin powders (GSP). The combined sensory evaluation approach, involving a descriptive and an affective test, respectively, was applied to evaluate the effect of the addition of grape skin powders from 2 grape varieties (Barbera and Chardonnay) at different levels [0.8, 1.6, and 2.4\%; weight (wt) powder/wt curd] on the sensory properties and consumer acceptability of innovative soft cow milk cheeses. The experimental plan envisaged 7 products, 6 fortified prototypes (at rates of Barbera and Chardonnay of $0.8,1.6$, and 2.4\%) and a control sample, with 1 wk of ripening. By means of a free choice profile, 21 cheese experts described the sensory properties of prototypes. A central location test with 90 consumers was subsequently conducted to assess the acceptability of samples. The GSP enrichment strongly affected the sensory properties of innovative products, mainly in terms of appearance and texture. Fortified samples were typically described with a marbling aspect (violet or brown as function of the grape variety) and with an increased granularity, sourness, saltiness, and astringency. The fortification also contributed certain vegetable sensations perceived at low intensity (grassy, cereal, nuts), and some potential negative sensations (earthy, animal, winy, varnish). The white color, the homogeneous dough, the compact and elastic texture, and the presence of lactic flavors resulted the positive drivers of preference. On the contrary, the marbling aspect, granularity, sandiness, sourness, saltiness, and astringency negatively affected the cheese acceptability for amounts of powder, exceeding 0.8 and $1.6 \%$ for the Barbera and Chardonnay prototypes, respectively. Therefore, the amount of powder resulted
\end{abstract}

Received June 7, 2015.

Accepted September 19, 2015.

${ }^{1}$ Corresponding author: 1.torri@unisg.it a critical parameter for liking of fortified cheeses and a discriminant between the 2 varieties. Reducing the GSP particle size and improving the GSP dispersion in the curd would reduce the effect of powder addition on sensory properties, thereby encouraging the use of these polyphenol-based fortifiers in cheeses. The proposed approach allowed the identification of sensory properties critical for product acceptability by consumers, thus helping the optimization of both fortifier characteristics and new cheese production and composition.

Key words: consumer acceptability, free-choice profile, soft cheese, grape skin powder

\section{INTRODUCTION}

Consumers are increasingly aware that food directly contributes to their health (Mollet and Rowland, 2002), and the dairy market plays an active role in health and wellness (Brockman and Beeren, 2011). The use of functional ingredients represents one of the most important trends in diary product technological innovation. Dairy product enrichment can include (1) fortification with microingredients (isolated and purified high-value compounds) to enhance the nutritional value of the food or (2) addition of macroingredients (complex ingredients, composed by a mixture of components). Within the first category, several examples are available, such as Bermúdez-Aguirre and Barbosa-Cánovas (2011), Rinaldoni et al. (2014), and Stratulat et al. (2014). Recently, winery by-products, such as grape pomace, were added as macroingredients to several foods to obtain novel functional food products enriched in terms of polyphenols and dietary fiber (Mildner-Szkudlarz et al., 2013; Yu and Ahmedna, 2013).

Several biological activities are reported for dietary fiber and polyphenols from grape pomace, and advantages from their use in dairy production processes, as well as in product quality, have been envisaged (Zhu et al., 2015). Environmental sustainability (Augustin et al., 2013) and contributions to managing waste (Fontana et al., 2013) are similarly important factors encouraging the use of nondairy products as ingredi- 
ents in the dairy industry. To our knowledge, among dairy products grape pomace has been uniquely used to fortify yogurt (Karaaslanet al., 2011; Codaet al., 2012) and salad dressing (Tseng and Zhao, 2013).

Beside the vast literature focusing on the advantages associated with the use of grape pomace as a food ingredient (Yu and Ahmedna, 2013; Zhu et al., 2015), a lack of information exists considering the sensory effect of this ingredient on food prototypes. Generally, the use of ingredients obtained by vegetal by-products to fortify or enrich foods contributes unpleasant sensations, which are detrimental to the overall quality (Ajila et al., 2010; Braghieri et al., 2015) and the acceptability (Marti et al., 2014; Rinaldoni et al., 2014) of food products. A limited number of studies have taken into account the effect of fortification with grape pomace on product sensory properties (Torri et al., 2015) and on its acceptability by consumers (Lavelli et al., 2014; Sant'Anna et al., 2014).

Belief in the health benefits from functional foods is the strongest positive determinant of consumer willingness to compromise on taste (Verbeke, 2006). Moreover, considering the appeal of nutrition and health claims, significant interaction effects were found between claim type and the product concept, indicating that consumers react differently to the product, functional ingredient, and claims of product function (Verbeke et al., 2009).

Thus, implementing healthy properties without taking into account taste modifications and consumer response to the new fortified food appears a highly speculative and risky strategic option (Verbeke, 2006). This aspect deserves even more attention in the case of fortification or enrichment of a familiar food. In fact, the more familiar is a consumer with the product the more deviation from the expected sensory properties will negatively affect the consumer's response (MildnerSzkudlarz et al., 2013). Based on these considerations, and given the importance of developing successful product for the food industry, it seems extremely important to include a consumer-based approach in product innovation and optimization process to investigate the effect of the fortification or enrichment on acceptability and to increase the probability of success in new products.

In the present study, a sensory- and consumer-based approach to optimize cheese enrichment or fortification conditions was proposed and applied to an innovative cow milk soft cheese developed by incorporating the grape skin powders (GSP) obtained from 2 grape varieties (Barbera, a red grape variety, and Chardonnay, a white grape variety) into the curd. The sensory- and consumer-based approach we present (1) evaluates the effect of enrichment conditions (type and concentration of added ingredient) on cheese sensory properties and (2) identifies the sensory drivers of the acceptability of the enriched soft cheeses developed in this study.

\section{MATERIALS AND METHODS}

\section{Products}

Grape Skin Powders. Grape pomace from nonfermented white Vitis vinifera cv. Chardonnay was provided by the Fontanafredda winemaking factory (Serralunga d'Alba, Cuneo, Italy), whereas that from fermented red Vitis vinifera cv. Barbera was provided by the Clarea winemaking factory (Chiomonte, Torino, Italy). The skins were mechanically separated, vacuum packaged, and stored at $-20^{\circ} \mathrm{C}$ before being dried in an oven (Memmert, UFE 550, Schwabach, Germany) at $54^{\circ} \mathrm{C}$ for $48 \mathrm{~h}$ and then ground with a Retsch ZM200 grinder (Retsch Gmbh, Haan, Germany) to obtain GSP with a particle size of less than $250 \mu \mathrm{m}$.

Cheese Samples. Raw cow milk (3.5\% protein, $3.6 \%$ fat, $5.1 \%$ lactose) was provided from a local farm, pasteurized at $72^{\circ} \mathrm{C}$ for $15 \mathrm{~s}$, and then calcium chloride $(0.1 \% \mathrm{vol} / \mathrm{vol})$ and mesophilic starter bacteria Lyofast MOSO60D (Clerici-Sacco, Cadorago, Italy) were added. Coagulation was performed at 38 to $40^{\circ} \mathrm{C}$ with cow rennet (chymosin-to-pepsin 20:80; Clerici, Milan, Italy). After 30 to 40 min of resting, the curd was cut 2 times and left to stand for $10 \mathrm{~min}$ at $37^{\circ} \mathrm{C}$. Ripening was performed at $6 \pm 1^{\circ} \mathrm{C}$ for $6 \mathrm{~d}$. During ripening, each cheese was manually dry salted. The obtained soft cheeses were fresh products similar to Robiola and considered as control sample (STD). Six samples of enriched cow milk soft cheese were developed by incorporating GSP from Barbera (B) and Chardonnay $(\mathbf{C})$ into the curd during the cheesemaking process. Three different percentages of powders $[0.8,1.6$, and $2.4 \%$; weight (wt) powder/wt curd] were added directly to the curd before shaping and manually mixed. A preliminary production test showed that it is not possible to obtain a cheese with a powder percentage higher than $2.5 \%$, as cheeses were not able to maintain their shape. The enriched samples were codified as B0.8, B1.6, B2.4, C0.8, C1.6, and $\mathrm{C} 2.4$. In total, the study used 7 cheese samples. At the end of ripening, the obtained cheeses $(250 \pm 10 \mathrm{~g})$ were cut in slices $(5 \times 3 \times 1.5 \mathrm{~cm})$ at room temperature $\left(20 \pm 1^{\circ} \mathrm{C}\right)$ approximately $20 \mathrm{~min}$ before each sensory evaluation. Slices were placed in transparent plastic cups (38 mL) and hermetically sealed with a clear plastic lid. Samples were identified with 3-digit codes, served in randomized and balanced order among subjects, and evaluated at room temperature $\left(20 \pm 1^{\circ} \mathrm{C}\right)$. 


\section{Methods}

Free Choice Profile. A group of 21 expert cheese tasters voluntarily participated in one session of the free choice profile. Assessors (male $=13$, female $=8$; aged 24 to $70 \mathrm{yr}$, mean age $=55 \mathrm{yr}$ ) were selected from among the tasters of the Italian National Cheese Taster Association (ONAF, Organizzazione Nazionale Assaggiatori Formaggio, Grinzane Cavour, Cuneo, Italy) and declared cheese consumption greater than 3 times a week. The session lasted 120 min. Sensory analysts briefed the experts on the methodology and the tasting procedure. The free choice profile session was divided in 2 parts separated by a 15-min break. In the first part, a vocabulary describing the sensory characteristics of prototypes was developed. The procedure required the assessors to observe, smell, and taste samples and describe the sensory characteristics of prototypes considering appearance, odor, taste, flavor, and texture freely using their own terms. Panelists were encouraged to use associative and cognitive terms, rather than quantitative or affective ones (such as good, bad, or intense). Next, the panelists were asked to select from their own list of self-elicited attributes those which they considered the most discriminative among samples. Each assessor freely selected the number of attributes to use. In the second part, a new set of the same samples was served (with different codes and in a different order) and assessors were asked to taste the samples and rate the intensity of sensations described by the attributes they selected using a 9-point scale ( $1=$ extremely weak, $9=$ extremely intense). Thus, in agreement with the literature (Guàrdia et al., 2010; Vit et al., 2011), assessors tasted each sample twice, evaluating the intensity of the descriptors once. The sample codes and presentation order were randomized across assessors in the 2 parts of the session. Instructions required the assessors to rinse their mouths with noncarbonated water before the beginning of the test. After each sample, subjects rinsed their mouths with water, had plain crackers for $30 \mathrm{~s}$, and finally rinsed their mouths with water for a further $30 \mathrm{~s}$. Subjects took a 1-min break between sample evaluations.

Consumer Test. A central location test with 90 consumers $($ male $=43$, female $=47$; aged 18 to $70 \mathrm{yr}$, mean age $=43 \mathrm{yr}$ ) was performed during the "Cheese 2013" International Cheese Exhibition (Bra, Cuneo, Italy). Consumers voluntarily participated in the sensory test. Demographic information (age: 18-35, 36-55, 56-70 yr; sex: male, female; nationality: Italian, nonItalian), socio-economic information (educational level: primary, high school, college, bachelor, other advanced degrees; occupational status: student, worker, retired, unemployed), and frequency of cheese consumption (once or less a week, 2-3 times a week, 4-5 times a week, once a day, more than once a day) were collected. Participants received individual trays with the 7 cheese samples and rinsed their mouths with noncarbonated water before beginning the evaluation. Participants tasted the samples according to the tray presentation order and in blind conditions, without any information about the innovativeness of the cheeses to avoid a potential effect of the information on liking scores. Participants rated their liking for appearance, odor, taste, flavor, texture, and overall liking using a 9-point hedonic scale $(1=$ extremely dislike, $9=$ extremely like; Peryam and Pilgrim, 1957). Cheese prototypes were served in a randomized and balanced order. The subjects followed the same rinsing procedure adopted in free choice profile.

\section{Data Analysis}

Free Choice Profile. Data collected using the free choice profile were submitted to generalized Procrustes analysis (GPA) to obtain a consensus map (Gower, 1975) by using the software Senstools v. 1.2x (OP\&P Product Research BV, Utrecht, the Netherlands). To estimate the significance of the GPA results, a permutation test was carried out (500 permutations were conducted on the raw matrix) and the total accounted variance of first dimensions was considered.

Consumer Test. The effect of the amount of GSP on liking in terms of appearance, odor, taste, flavor, texture, and overall liking was assessed using a 2-way ANOVA mixed model with interactions (fixed factor: GSP amount, 3 levels $=0.8,1.6,2.4 \%$; random factors: subjects). The effect of grape variety on liking in terms of appearance, odor, taste, flavor, texture, and overall liking was assessed using a 2-way ANOVA mixed model with interactions (fixed factor: grape variety, 2 levels = Barbera, Chardonnay; random factors: subjects). A 2-way ANOVA mixed model with interactions was used to estimate the effect of the product on the overall liking and on liking in all sensory modalities (fixed factor: product, 7 levels; random factors: subjects). A partial least square regression (PLS) was performed for exploratory purposes, considering the sensory data from free choice profile as the $\mathrm{X}$ data set and the overall liking of 90 consumers as the $\mathrm{Y}$ data set. To select the most discriminating attributes, those with a loading equal to or greater than 0.7 (absolute value) on the GPA consensus map for the first 2 principal dimensions (Dim1 or Dim2) were selected to create the matrix. The PLS was performed using The Unscrambler X software, version 10.3 (Camo Software AS, Oslo, Norway). Analysis of variance analyses were conducted using 
Systat software, version 13.1 (Systat Software Inc., San José, CA).

\section{RESULTS}

\section{Cheese Sensory Properties}

Experts created 64 terms in total. The number of created attributes per subject ranged from a minimum of 4 to a maximum of 17 attributes. The average number of attributes created by experts was 8 , in agreement with findings in the literature (Guàrdia et al., 2010). The initial list of attributes was reduced to achieve a unique list that comprehensively and accurately described the product space; redundant or less-cited terms were grouped on a semantic basis or eliminated. The final list consisted of 54 descriptors classified according to sensory modality: appearance (7), aroma (11), taste and mouthfeel sensations (6), flavor (17), and texture (13; Table 1). Analysis of occurrences showed that the most frequently elicited descriptors (cited by at least one-third of experts at least 7 times) were marbling brown, white, odor and flavor of lactic, odor and flavor of yogurt, bitter, sour, and gummy.

Appearance resulted in a key sensory modality for sample discrimination with a relatively low number of descriptors (7) and a relatively high number of occurrences (31). New prototypes were generally described by using terms related to the marbling aspect (marbling, brown marbling, violet marbling, homogeneous marbling), homogeneous dough, white color, and by the presence of holes. The control sample was described as having a white color, which contrasted with the fortified samples.

Taste and mouthfeel were described using 4 attributes for fundamental tastes (sour, bitter, sweet, salty) and the tactile sensation of astringency with 35 occurrences in total. Sourness was the most used taste, elicited by 11 out of 21 judges. Bitter and salty tastes were cited 7 and 6 times, respectively, both showing higher intensity scores in the enriched samples compared with the reference standard. Judges cited astringency only 3 times. For 2 assessors this attribute had high loading values on Dim2, but it was perceived in a contrasting way by judges.

Considering the olfactory sensations, judges used a high number of attributes to describe odor and flavor (11 and 17 terms, respectively). Among these descriptors, several terms described vegetable sensations (cereal, grassy, fruity, citric, nuts, vanilla), whereas other terms were not related to food and tended to have a negative connotation (earthy, varnish, ammonia, acetone, animal, metallic, winy). However, a low number of judges elicited odor and flavor sensations, and most of the sensations in this sensory modality occurred fewer than 3 times. The odor and flavor of lactic acid and the odor and flavor of yogurt were the only attributes with several occurrences equal to or higher than 7 . These 2 sensations typically characterized the perception of cheese.

Texture was extremely important in discriminating among samples, showing the highest number of occurrences (41). Judges mainly used the attributes gummy, adhesive, elastic, and granular, with the last one clearly characterizing the enriched samples. The attributes sandy, creamy, and compact had low occurrences but showed high loading values on the consensus map.

The experts' individual configurations were submitted to GPA. The permutation test indicated a probability of less than $0.05 \%$ that the consensus generated in the study could have arisen by chance. The consensus space obtained from GPA and applied to individual configuration is depicted in Figure 1. The total variance explained by the first 2 dimensions accounted for 39 and $15 \%$ on Dim1 and Dim2, respectively. Samples were clearly discriminated according to the percentage of GSP along Dim1. The reference sample was positively correlated with Dim1 and is highly correlated with white color, homogeneous dough, gumminess, sweet, bitter, and lactic sensations. Judges also detected an animal flavor in this sample. Fortified samples tend to move on the left side of Dim1 as a function of their GSP content. In general, sourness, saltiness, and bitterness tended to increase as a function of the amount of GSP added, independent of the grape variety.

The grape variety showed a significant effect on sensory properties along Dim2. In particular, all samples containing Barbera GSP were on the lower part of the map, whereas samples with Chardonnay GSP spread in the upper quadrant of the map. The grape variety affects the prototype color and marbling descriptors (marbling, marbling violet, marbling brown) along Dim1. In particular, B2.4 and B1.6 were closely associated with intense violet marbling and samples C2.4 and C1.6 had a brown marbling appearance.

Grape variety also influenced the relative differences among samples fortified with increasing amounts of the same GSP. The perceived differences between C1.6 and $\mathrm{C} 2.4$ were greater than those detected between B1.6 and B2.4, as shown by the relative distance between samples on the map; specifically, the perceived difference was higher between C1.6 and C2.4 than between $\mathrm{B} 1.6$ and B2.4. It is possible to assume that the higher color intensity perceived in cheese prepared with 1.6 and $2.4 \%$ of Barbera GSP with respect to B0.8 tend to suppress the perception of other sensory differences between this pair of samples. Both $\mathrm{C} 0.8$ and B0.8 were shown to be quite similar in terms of appearance and 
texture, with B0.8 being associated with granularity and crumbliness sensations whereas $\mathrm{C} 0.8$ was described as more gummy and having a clearer color. Samples
C1.6 and C2.4 were positively correlated with Dim2 and were primarily described as sandy, creamy, sour, bitter, and astringent.

Table 1. Descriptors used by experts divided on sensory modalities, number of occurrences of each descriptor in the data set and number of occurrences of each construct

\begin{tabular}{|c|c|c|c|c|c|c|c|}
\hline \multirow[b]{2}{*}{ Sensory Modality } & \multirow[b]{2}{*}{ Descriptor } & \multirow[b]{2}{*}{ Occurrences } & \multirow[b]{2}{*}{$\mathrm{O} / \mathrm{SM}^{1}$} & \multicolumn{2}{|c|}{$\operatorname{Dim1}^{2}(39 \%)$} & \multicolumn{2}{|c|}{$\operatorname{Dim} 2^{2}(15 \%)$} \\
\hline & & & & + & - & + & - \\
\hline \multirow{7}{*}{ Appearance } & Holes & 5 & 31 & 0 & 0 & 0 & 0 \\
\hline & Homogeneous_dough & 2 & & 1 & 0 & 0 & 0 \\
\hline & Homogeneous_marbling & 2 & & 0 & 2 & 0 & 0 \\
\hline & Marbling & 3 & & 0 & 3 & 0 & 0 \\
\hline & Marbling_brown & 7 & & 0 & 6 & 0 & 0 \\
\hline & Marbling_violet & 4 & & 0 & 2 & 0 & 0 \\
\hline & White & 8 & & 5 & 0 & 0 & 0 \\
\hline \multirow[t]{11}{*}{ Odor (O) } & O-Cereal & 2 & 30 & 0 & 0 & 0 & 0 \\
\hline & O-Citric & 1 & & 0 & 1 & 0 & 0 \\
\hline & O-Cream & 1 & & 0 & 1 & 0 & 0 \\
\hline & O-Earthy & 1 & & 0 & 1 & 0 & 0 \\
\hline & O-Fruity & 2 & & 0 & 0 & 0 & 0 \\
\hline & O-Grassy & 1 & & 0 & 0 & 0 & 0 \\
\hline & O-Lactic & 7 & & 1 & 1 & 0 & 0 \\
\hline & O-Nuts & 2 & & 0 & 0 & 0 & 0 \\
\hline & O-Varnish & 1 & & 0 & 1 & 0 & 0 \\
\hline & O-Winy & 4 & & 0 & 0 & 0 & 0 \\
\hline & O-Yogurt & 8 & & 0 & 1 & 0 & 0 \\
\hline \multirow[t]{6}{*}{ Taste and mouthfeel } & Bitter & 7 & 36 & 1 & 1 & 1 & 0 \\
\hline & Salty & 6 & & 0 & 3 & 0 & 0 \\
\hline & Sour & 11 & & 0 & 5 & 1 & 0 \\
\hline & Spicy & 3 & & 0 & 0 & 0 & 0 \\
\hline & Sweet & 5 & & 2 & 1 & 0 & 0 \\
\hline & Astringent & 3 & & 0 & 0 & 1 & 1 \\
\hline \multirow[t]{17}{*}{ Flavor $(\mathrm{F})$} & F-Acetic & 1 & 35 & 0 & 0 & 0 & 0 \\
\hline & F-Acetone & 1 & & 0 & 0 & 0 & 0 \\
\hline & F-Ammonia & 1 & & 0 & 0 & 0 & 0 \\
\hline & F-Animal & 1 & & 1 & 0 & 0 & 0 \\
\hline & F-Citric & 2 & & 0 & 1 & 0 & 0 \\
\hline & F-Cream & 3 & & 0 & 0 & 0 & 0 \\
\hline & F-Earthy & 1 & & 0 & 1 & 0 & 0 \\
\hline & F-Grassy & 1 & & 0 & 0 & 0 & 0 \\
\hline & F-Lactic & 8 & & 1 & 0 & 0 & 0 \\
\hline & F-Floury & 2 & & 0 & 0 & 0 & 0 \\
\hline & F-Metallic & 1 & & 0 & 0 & 0 & 0 \\
\hline & F-Nuts & 2 & & 0 & 1 & 0 & 0 \\
\hline & F-Toasted & 2 & & 0 & 0 & 0 & 0 \\
\hline & F-Vanilla & 1 & & 0 & 0 & 0 & 0 \\
\hline & F-Winy & 1 & & 0 & 0 & 0 & 0 \\
\hline & F-Yogurt & 7 & & 0 & 0 & 1 & 0 \\
\hline & F-Overall intensity & 1 & & 0 & 0 & 0 & 0 \\
\hline \multirow[t]{13}{*}{ Texture } & Adhesive & 5 & 41 & 1 & 0 & 0 & 0 \\
\hline & Compact & 3 & & 1 & 0 & 1 & 0 \\
\hline & Creamy & 2 & & 0 & 0 & 2 & 0 \\
\hline & Crumbly & 1 & & 0 & 0 & 0 & 1 \\
\hline & Doughy & 4 & & 0 & 1 & 0 & 0 \\
\hline & Elastic & 5 & & 1 & 0 & 0 & 0 \\
\hline & Granular & 5 & & 0 & 2 & 0 & 1 \\
\hline & Gummy & 8 & & 2 & 0 & 0 & 0 \\
\hline & Sandy & 3 & & 0 & 0 & 2 & 0 \\
\hline & Soft & 1 & & 0 & 1 & 0 & 0 \\
\hline & Soluble & 2 & & 0 & 1 & 0 & 0 \\
\hline & Sticky & 1 & & 0 & 0 & 0 & 0 \\
\hline & Watery & 1 & & 0 & 0 & 0 & 0 \\
\hline Total & 54 & 173 & 173 & 17 & 37 & 9 & 3 \\
\hline
\end{tabular}

${ }^{1} \mathrm{O} / \mathrm{SM}=$ number of occurrences per sensory modality.

${ }^{2}$ Descriptors with a vector loading $\leq 0.7$ or $\geq 0.7$ on the first two dimensions (Dim) of general Procrustes analysis have been included. A descriptor can have a loading on more than one axis. 


\section{Cheese Liking}

Results from the 2-way mixed ANOVA model did not reveal a significant effect $(F=0.921 ; P=0.34)$ of the grape variety on the overall liking expressed by all 90 consumers $(\mathrm{B}=5.0 \pm 0.1 ; \mathrm{C}=5.1 \pm 0.1)$. A signifi- cant effect of the GSP percentage on the overall liking was found $(F=9.10 ; P<0.01)$. In particular, the overall liking significantly decreased with the increase of GSP; prototypes with the lowest percentage of GSP $(0.8 \%)$ obtained the highest overall liking scores $(5.3$ \pm 0.1 ) whereas the prototypes with $2.4 \%$ of GSP were

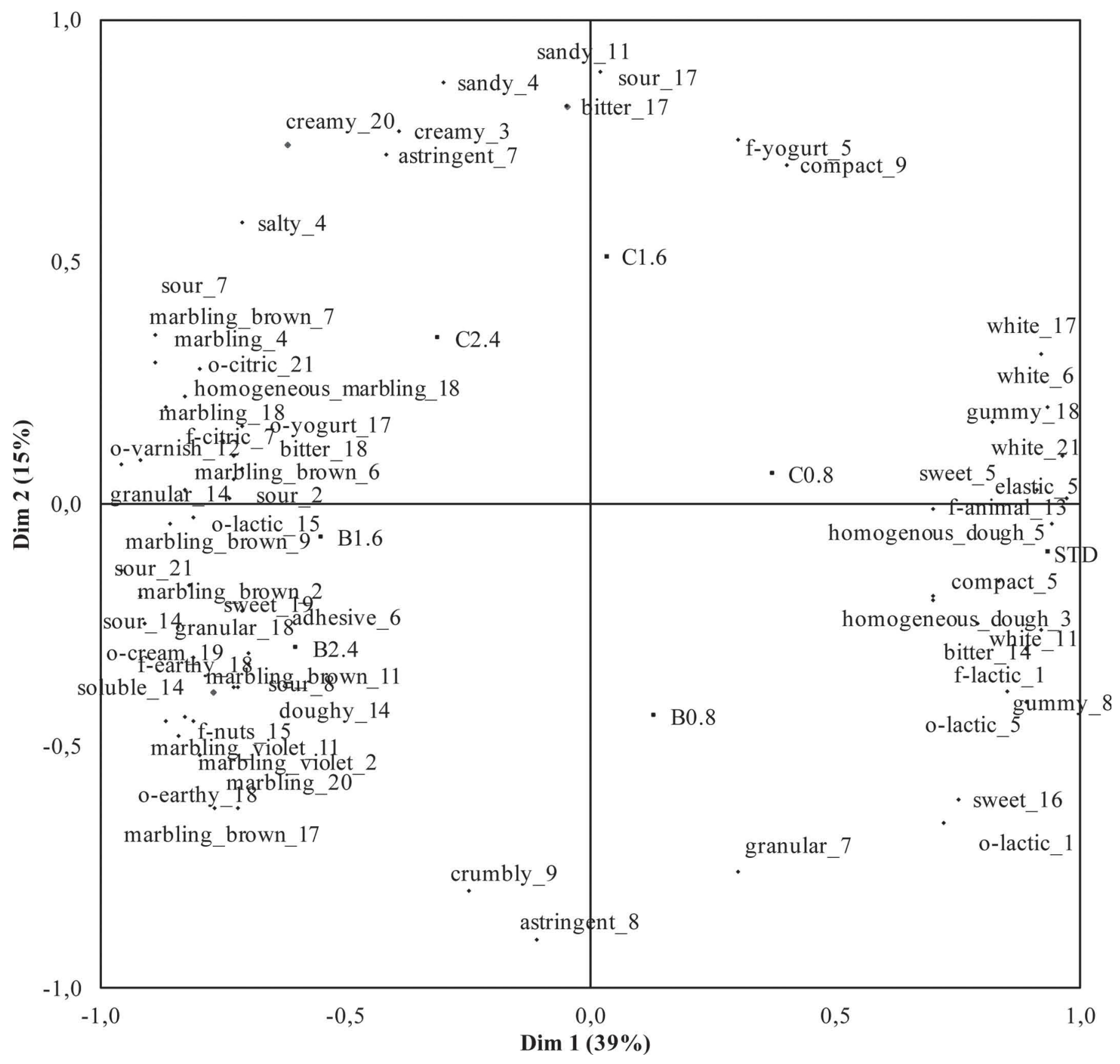

Figure 1. Consensus maps obtained from general Procrustes analysis (GPA) applied on the free-choice profile data conducted with 21 experts. Individual configurations and sample positioning are depicted. Descriptors with a vector loading $\leq 0.7$ or $\geq 0.7$ on the first 2 dimensions (Dim) are shown. Individual attributes are indicated by the name of the attribute itself and the number of judge who used the descriptor. Letters $\mathrm{o}$ and $\mathrm{f}$ represent odor and flavor, respectively. Samples: $\mathrm{B}=$ Barbera grape variety; $\mathrm{C}=$ Chardonnay grape variety; $0.8=0.8$ grape skin powders/curd, wt/wt basis; $1.6=1.6$ grape skin powders/curd, wt/wt basis; $2.4=2.4$ grape skin powders/curd, wt/wt basis. 
Table 2. Overall liking and liking for appearance, odor, taste, flavor, and texture of the cheese samples expressed by 90 consumers $^{1}$

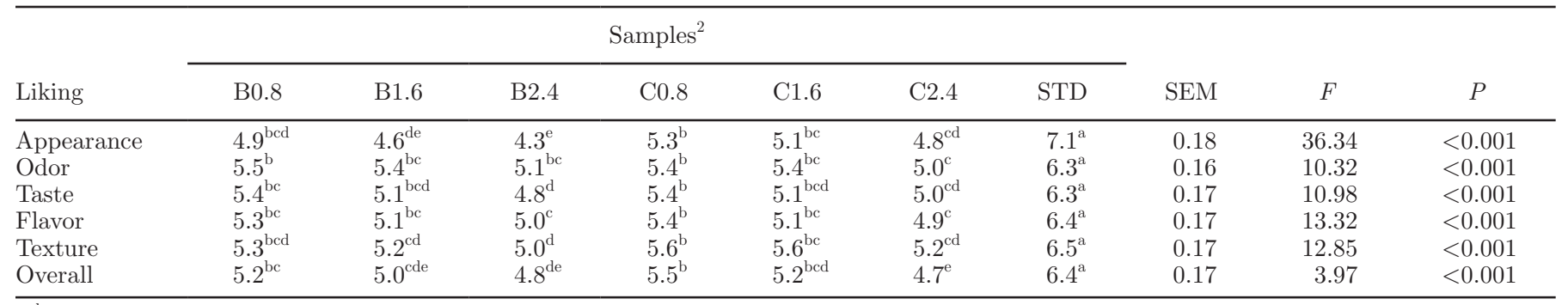

${ }^{\mathrm{a}-\mathrm{d}}$ Different letters within a row indicate significant differences $(P<0.05)$ between mean values.

${ }^{1}$ Table shows results from 2-way mixed ANOVA models (fixed factor: product; random factor: subject, interaction product/subject). Fisher's Least Significance Difference post hoc test was conducted on the data set of 90 subjects.

${ }^{2}$ Samples: $\mathrm{B}=$ Barbera grape variety; $\mathrm{C}=$ Chardonnay grape variety; $0.8=0.8$ grape skin powders $/$ curd, wt $/$ wt basis; $1.6=1.6$ grape skin powders/curd, wt/wt basis; $2.4=2.4$ grape skin powders/curd, wt/wt basis.; STD = control, not fortified.

the least preferred $(4.8 \pm 0.1)$. A significant effect of product $(P<0.001)$ was found on liking as expressed by 90 consumers considering the appearance, odor, taste, flavor, texture, and overall liking (Table 2). The reference sample was the most liked according to scores relevant to all the sensory modalities. The addition of GSP to the cheese induced a significant decrease in liking ratings $(P<0.05)$.

According to the overall liking ratings, all fortified samples ranged from 4.7 to 5.5 (Tab. 2). In particular, $\mathrm{C} 0.8, \mathrm{~B} 0.8$, and $\mathrm{C} 1.6$ obtained the highest average scores, C2.4 received the lowest mean value with no significant differences from samples B0.8, and B1.6. C0.8, C1.6, and B0.8 showed the highest mean scores for the appearance. Barbera samples fortified with 1.6 and $2.4 \%$ of GSP tended to be the least preferred samples in terms of the appearance. Results showed only slight differences among samples in liking for the aroma. Samples containing the lowest and intermediate GSP amount (B0.8, B1.6, C0.8, and C1.6) tended to be more preferred than B2.4 and $\mathrm{C} 2.4$ in terms of taste and flavor. Considering the texture, $\mathrm{C} 0.8$ had the highest score, with the mean rate not significantly different from B0.8 and C1.6. Samples with the highest amount of GSP (B2.4, and C2.4) had the lowest texture ratings, with a mean rate not significantly different from B0.8 and B1.6.

\section{Relationship Between Sensory Properties and Hedonic Responses}

The map obtained by the PLS regression performed for exploratory purposes shows the relationship between the hedonic responses of 90 consumers and the sensory properties of the samples (Figure 2). The map indicates consumers' clear preference for the reference sample, as shown by the high concentration of consum- ers positioned on the right part of the map. The sensory properties characterizing the standard tended to be the positive drivers of the overall liking, particularly the white color, the homogeneous dough, the compact and elastic texture, and the presence of lactic flavors. On the contrary, all sensations perceived at high intensity in samples with a high amount of GSP appeared to be negative drivers of overall liking, particularly for attributes describing the marbling appearance (violet and brown), the intense sourness and the perception of granularity and sandiness, together with some odors and flavors (varnish, earthy, citric). In general, the analysis of the preferences suggests the importance of reducing the sandiness and granular sensations associated with the less liked cheeses to match consumer preferences, as well as to reduce the perceived intensity of sourness.

Results showed an inverse relationship between the amount of GSP added and the acceptability of prototypes. In general, GSP addition clearly induced lower consumer liking for prototypes. This effect was more evident in Barbera than Chardonnay samples. In fact, strong liking decreased as the amount of Barbera GSP increased from 0.8 to $1.6 \%$, whereas only a slight change in liking occurred for the same range of GSP variation in the Chardonnay samples. Grape variety clearly affects consumer preference for fortified prototypes. In particular, a visual inspection of PLS regression plot shows that consumers tended to be almost equally distributed along Dim2 between the upper and lower quadrants of the map. This finding suggested the presence of 2 distinct groups of subjects. One group, composed of the consumers located in the upper right quadrant, preferred the samples prepared with the white grape variety (Chardonnay). The other group, located in the lower right quadrant, tended to prefer samples prepared with the red grape variety (Barbera). Results confirmed this finding by computing the mean 


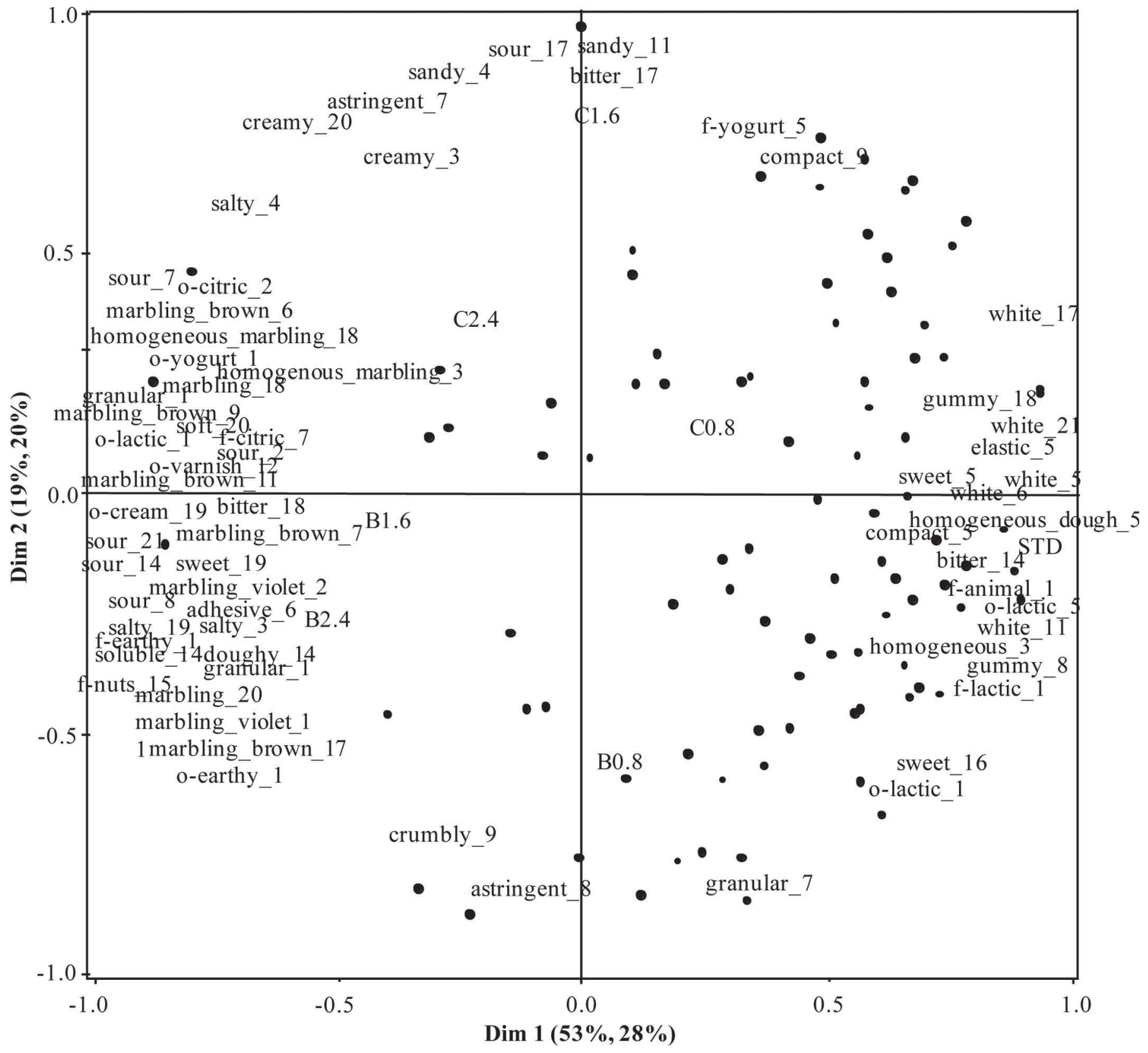

Figure 2. Map obtained from partial least square regression (PLS) performed considering X data set as the sensory data from free-choice profile and $\mathrm{Y}$ data set as the overall liking of 90 consumers. The first and the second percentage on each axis express the variability explained by the $\mathrm{X}$ and $\mathrm{Y}$ data set, respectively. Descriptors with a vector loading $\leq 0.7$ or $\geq 0.7$ on the first 2 dimensions (Dim) of general Procrustes analysis have been included. Individual attributes are indicated by the name of the attribute itself and the number of judge who used the descriptor. Letters o and $\mathrm{f}$ represent odor and flavor, respectively. $\mathbf{-}=$ consumers' samples: $\mathrm{B}=$ Barbera grape variety; $\mathrm{C}=\mathrm{Chardonnay} \mathrm{grape} \mathrm{variety;} 0.8$ $=0.8$ grape skin powders/curd, wt/wt basis; $1.6=1.6$ grape skin powders/curd, wt/wt basis; $2.4=2.4$ grape skin powders/curd, wt/wt basis .

overall liking ratings of the 2 separate groups (the first positioned in the right upper quadrant, the second in the lower right quadrant). Both groups preferred the standard sample but among the fortified samples, the former segment preferred samples C1.6 $(6.3 \pm 0.2)$ and $\mathrm{C} 0.8(5.5 \pm 0.3)$, whereas the latter group preferred the cheese B0.8 (5.7 \pm 0.2$)$.

\section{DISCUSSION}

\section{Effect of the Addition of GSP on Cheese Sensory Properties}

Considering the frequency of the occurrence of sensory attributes used in free choice profile, the most 
frequent attributes mentioned by experts were related to taste (sourness elicited by 11 out of 21 experts) and appearance, particularly the marbling aspect (16 elicitations in total considering marbling, violet marbling, brown marbling, and homogeneous marbling). These results confirm the importance of the visual inspection in the description and appreciation of food products (Dinnella et al., 2014). This result could be partially explained by recalling that, generally, visual attributes are easier to describe than the olfactory and gustative sensations because vision and hearing are inborn mechanisms, whereas the other senses rely largely on learning (Köster, 2003).

The visual inspection of the consensus map obtained from the GPA clearly showed the strong effect of GSP fortification on the sensory properties of the new developed prototypes. Considering the appearance, the high amount of colored phenol compounds contained in red grape skins from Barbera and released from the GSP into the cheese induced a violet and brown marbling, a color that was not present in the reference sample. Other studies showed an analogous effect on food color induced by the use of phenol based winery by-products in biscuits (Mildner-Szkudlarz at al., 2013; Pasqualone et al., 2014). Moreover, the addition of GSP strongly affected the cheese texture. In particular, the granularity sensation perceived in the soft cheese was probably due the particle size of GSP used, which was under $250 \mu \mathrm{m}$. This particle size is above the perception threshold, estimated to be approximately $25 \mu \mathrm{m}$ (Hinton, 1970), and hard and irregular particles can produce gritty sensations even at sizes less than $10 \mu \mathrm{m}$ (Utz, 1986). In agreement with our findings, the addition of solid particles in a food matrix increased the sensation of roughness and significantly decreased the ratings of several texture attributes, such as smooth, creamy, fatty, and slippery (Engelen et al., 2005). Considering soft model systems containing solid particles, larger particle sizes and higher concentrations reduced creaminess (Kilcast and Clegg, 2002). Moreover, both the concentration and the particles size influenced grittiness (Imai et al., 1997), as well as the shape and surface of particles (Tyle, 1993; Engelen et al., 2005). Thus, a finer and rounder particle for GSP could help to reduce the perceived sensation of granularity, which was one of the sensory properties responsible for decreasing overall liking in the cheese prototypes. In agreement with data from the literature, GSP from both grape varieties contributes a sour taste and peculiar vegetable ortho- and retro-olfactory sensations such as grassy, winy, fruity, citric, cereal, nut, toasted, and spicy (Pasqualone et al., 2014).

\section{Effect of the GSP Addition on Consumer Preference}

In studies about food acceptability, a critical question is, "To what extent the variation in perceived sensory characteristics influences consumer response?" (Bayarri et al., 2011). In certain cases, sensory differences among products do not affect the acceptability (Costell et al., 2010), whereas in other cases, the sensory properties strongly influence liking (Murray and Delahunty, 2000).

In the present study, the addition of GSP significantly affected the acceptability of the newly developed samples, inducing a decrease in the liking ratings for all considered sensory modalities $(P<0.05)$. This result is in complete agreement with Sant'Anna et al. (2014), who recently reported a decrease in the liking for aroma, aftertaste, flavor, and appearance in fettuccine pasta fortified with grape marc powder. Consumer familiarity with conventional unfortified food (such as commercially available fettuccini pasta or soft cheese) and clear expectations about their sensory properties probably accounts for the low acceptability found for fortified versions of food (Wardle and Cooke, 2008; Sant'Anna et al., 2014). It is noteworthy that the level of familiarity with a food strongly influences its acceptability by consumers,

In agreement with our findings, Rinaldoni et al. (2014) also reported that the spreadable cheese-like products supplemented with the lowest degree of soybean protein had the best hedonic performance in terms of overall liking. These results clearly show that the functionalization of products obtained by the addition of a powdery ingredient (i.e., powder) could negatively affect consumer liking; consequently, the amount of the added material is a crucial parameter when developing new prototypes. Moreover, the amount of powder that can be added without lowering liking below the level of acceptability depends on the considered matrix to which the powder is added. Our study indicated that, in soft cow cheeses, although $0.8 \%$ was the critical acceptability threshold in the case of cheeses prepared with Barbera GSP, consumers tolerated an amount of $1.6 \%$ of Chardonnay GSP in cheese without further negative effects on sample acceptability. It could be hypothesized that the violet marbling of Barbera samples appeared more unusual to consumers, who then became less inclined to compromise on flavor compared with those consumers who preferred the Chardonnay samples enriched at 0.8 and $1.6 \%$.

Because the difference between the 2 grape varieties was evident mainly in terms of the color of the marbling aspect, the color was the main sensory property discriminating between the 2 blocks of samples. Similarly, a recent study (Braghieri et al., 2015) on the accept- 
ability of Scamorza cheeses enriched with peptidolytic adjunct showed higher values of overall liking for standard samples compared with enriched samples. In some cases, the fortification of cheese with health-related compounds did not play a significant role for the liking of color expressed by consumers (Bermúdez-Aguirre and Barbosa-Cánovas, 2011). However, color influenced consumer acceptability of low-fat cheeses with added annatto colorant (Wadhwani and McMahon, 2012). Similarly, in the present study, the deviation from the white color characterizing the reference sample compared with the marbling aspect of the enriched samples negatively affected the latter's acceptability. Presumably, consumers perceived the intense violet and brown marbling characterizing of samples with the highest amount of GSP (B2.4 and C2.4) as overly strange or not appropriate for a fresh cheese.

Collecting sensory information allowed us to develop new fortified or enriched products with an increased probability to meet the consumer acceptance, a factor which could not be neglected, especially when dealing with food products very familiar to consumers such as cheese. Our study showed the feasibility of developing soft cow milk cheese enriched with GSP; however, the amount of GSP added to cheeses resulted a critical parameter for the acceptability of innovative prototypes. To obtain satisfactory results in terms of consumer hedonic responses, no more than $0.8 \%$ should be added to samples prepared with the red grape variety, Barbera, whereas the threshold for samples prepared with the white grape variety, Chardonnay, should not exceed $1.6 \%$. The fortification with GSP strongly influenced the sensory properties of new prototypes, particularly considering the texture and the appearance. High amounts of GSP were generally associated with an increase in the perceived marbling aspect, granularity, sandiness, sourness, saltiness, and astringency. All samples were described as having a lactic flavor, but fortification generally added certain vegetable sensations (grassy, cereal, nuts) in combination with other sensations sometimes perceived as possible defects (earthy, animal, winy, varnish). For fortification, the amount of GSP added played the main role in modifying the sensory properties of soft cheeses; however, the grape variety was also important for the color modifications, with the Barbera and Chardonnay samples being noted for their violet and brown marbling aspect, respectively. This differentiation of the prototypes based on the grape variety tended to discriminate consumers into 2 groups with opposite preferences for violet- and brown-colored cheeses. Therefore, in our study, the grape variety (intended as a modifier of the product appearance, particularly in terms of color) represented an opportunity to differentiate cheeses. In the future, a marketing strategy aiming to inform consumers about the addition powder from Barbera and Chardonnay GSP to cheeses could be developed and represent a good opportunity to differentiate prototypes suitable to satisfy the needs of different consumer segments with opposing preferences. However, the optimization of the prototype is suitable, particularly considering (1) the reduction of the GSP particle size, possibly beyond the perception threshold, and (2) the improvement of the dispersion of GSP in the milk curd.

\section{CONCLUSIONS}

Cheese is probably not a good vehicle for fortification with GSP, as the sensory- and consumer-based adopted approach allowed us (1) to identify the effect of the addition of the GSP on the sensory properties of soft cheese, (2) to point out which sensory properties were detrimental for the product acceptability by consumers, and (3) to obtain information to optimize the ingredient characteristics and the process conditions.

\section{ACKNOWLEDGMENTS}

This research was supported by AGER-Agroalimentare e ricerca, Milan, Italy (contract number 20102222). The authors thank the Fontanafredda (Serralunga d'Alba, Cuneo, Italy) and Clarea (Chiomonte, Torino, Italy) winemaking factories for providing the grape pomace used in this study and the 21 assessors of the Italian National Cheese Taster Association (ONAF, Organizzazione Nazionale Assaggiatori Formaggio, Grinzane Cavour, Cuneo, Italy) for their participation in the Free Choice Profile evaluation.

\section{REFERENCES}

Ajila, C. M., M. Aalami, K. Leelavathi, and U. J. S. Prasada Rao. 2010. Mango peel powder: A potential source of antioxidant and dietary fiber in macaroni preparations. Innov. Food Sci. Emerg. Technol. 11:219-224. http://dx.doi.org/10.1016/j.ifset.2009.10.004.

Augustin, M. A., P. Udabage, P. Juliano, and P. T. Clarke. 2013. Towards a more sustainable dairy industry: Integration across the farmfactory interface and the dairy factory of the future. Int. Dairy J. 31:2-11. http://dx.doi.org/10.1016/j.idairyj.2012.03.009.

Bayarri, S., I. Carbonell, E. X. Barrios, and E. Costell. 2011. Impact of sensory differences on consumer acceptability of yoghurt and yoghurt-like products. Int. Dairy J. 21:111-118. http://dx.doi. org/10.1016/j.idairyj.2010.09.002.

Bermúdez-Aguirre, D., and G. V. Barbosa-Cánovas. 2011. Quality of selected cheeses fortified with vegetable and animal sources of omega-3. LWT Food Sci. Technol. (Campinas) 44:1577-1584. http://dx.doi.org/10.1016/j.lwt.2011.01.023.

Braghieri, A., N. Piazzolla, A. Romaniello, F. Paladino, A. Ricciardi, and F. Napolitano. 2015. Effect of adjuncts on sensory properties and consumer liking of Scamorza cheese. J. Dairy Sci. 98:1479 1491. http://dx.doi.org/10.3168/jds.2014-8555. 
Brockman, C., and C. J. M. Beeren. 2011. Consumer perceptions of additives in dairy products. Pages 41-48 in Encyclopedia of Dairy Sciences. 2nd ed. J. W. Fuquay, ed. Elsevier Ltd., Cambridge, UK.

Coda, R., A. Lanera, A. Trani, M. Gobbetti, and R. Di Cagno. 2012. Yogurt-like beverages made of a mixture of cereals, soy and grape must: microbiology, texture, nutritional and sensory properties. Int. J. Food Microbiol. 155:120-127. http://dx.doi.org/10.1016/j. ijfoodmicro.2012.01.016.

Costell, E., A. Tárrega, and S. Bayarri. 2010. Food acceptance: The role of consumer perception and attitudes. Chemosens. Percept. 3:42-50. http://dx.doi.org/10.1007/s12078-009-9057-1.

Dinnella, C., L. Torri, G. Caporale, and E. Monteleone. 2014. An exploratory study of sensory attributes and consumer traits underlying liking for and perceptions of freshness for ready to eat mixed salad leaves in Italy. Food Res. Int. 59:108-116.

Engelen, L., R. a. De Wijk, A. van der Bilt, J. F. Prinz, A. M. Janssen, and F. Bosman. 2005. Relating particles and texture perception. Physiol. Behav. 86:111-117. http://dx.doi.org/10.1016/j. physbeh.2005.06.022.

Fontana, A. R., A. Antoniolli, and R. Bottini. 2013. Grape pomace as a sustainable source of bioactive compounds: Extraction, characterization, and biotechnological applications of phenolics. J. Agric. Food Chem. 61:8987-9003.

Gower, J. C. 1975. Generalized procrustes analysis. Psychometrika 40:33-51.

Guàrdia, M. D., A. P. S. Aguiar, A. Claret, J. Arnau, and L. Guerrero. 2010. Sensory characterization of dry-cured ham using freechoice profiling. Food Qual. Prefer. 21:148-155. http://dx.doi. org/10.1016/j.foodqual.2009.08.014.

Hinton, C. L. 1970. Particle fineness in chocolate and its measurement. Page 111 in Twenty Years of concectionery and chocolate progress. C. D. Pratt, E. de Vadetsky, K. E. Landwill, K. E. McCloskey, and H. W. Schuemann, ed. Avi Publishing Co., Westport, CT.

Imai, E., Y. Shimichi, I. Maruyama, A. Inoue, S. Ogawa, K. Hatae, and A. Shimada. 1997. Perception of grittiness in an oilin-water emulsion. J. Texture Stud. 28:257-272. http://dx.doi. org/10.1111/j.1745-4603.1997.tb00116.x.

Karaaslan, M., M. Ozden, H. Vardin, and H. Turkoglu. 2011. Phenolic fortification of yogurt using grape and callus extracts. LWT Food Sci. Technol. (Campinas) 44:1065-1072. http://dx.doi. org/10.1016/j.lwt.2010.12.009.

Kilcast, D., and S. Clegg. 2002. Sensory perception of creaminess and its relationship with food structure. Food Qual. Prefer. 13:609 623. http://dx.doi.org/10.1016/S0950-3293(02)00074-5.

Köster, E. P. 2003. The psychology of food choice: Some often encountered fallacies. Food Qual. Prefer. 14:359-373. http://dx.doi. org/10.1016/S0950-3293(03)00017-X.

Lavelli, V., P. S. C. Sri Harsha, L. Torri, and G. Zeppa. 2014. Use of winemaking by-products as an ingredient for tomato puree: The effect of particle size on product quality. Food Chem. 152:162-168. http://dx.doi.org/10.1016/j.foodchem.2013.11.103.

Marti, A., L. Torri, M. C. Casiraghi, L. Franzetti, S. Limbo, F. Morandin, L. Quaglia, and M. A. Pagani. 2014. Wheat germ stabilization by heat-treatment or sourdough fermentation: effects on dough rheology and bread properties. LWT Food Sci. Technol. (Campinas) 59:1100-1106. http://dx.doi.org/10.1016/j.lwt.2014.06.039.

Mildner-Szkudlarz, S., J. Bajerska, R. Zawirska-Wojtasiak, and D. Górecka. 2013. White grape pomace as a source of dietary fibre and polyphenols and its effect on physical and nutraceutical characteristics of wheat biscuits. J. Sci. Food Agric. 93:389-395.

Mollet, B., and I. Rowland. 2002. Functional foods: At the frontier between food and pharma. Curr. Opin. Biotechnol. 13:483-485.
Murray, J., and C. Delahunty. 2000. Mapping consumer preference for the sensory and packaging attributes of Cheddar cheese. Food Qual. Prefer. 11:419-435. http://dx.doi.org/10.1016/S09503293(00)00017-3.

Pasqualone, A., A. M. Bianco, V. M. Paradiso, C. Summo, G. Gambacorta, and F. Caponio. 2014. Physico-chemical, sensory and volatile profiles of biscuits enriched with grape marc extract. Food Res. Int. http://dx.doi.org/10.1016/j.foodres.2014.07.014.

Peryam, D. R., and F. J. Pilgrim. 1957. Hedonic scale method of measuring food preferences. Food Technol. 11:9-14.

Rinaldoni, A. N., D. R. Palatnik, N. Zaritzky, and M. E. Campderrós. 2014. Soft cheese-like product development enriched with soy protein concentrates. LWT Food Sci. Technol. (Campinas) 55:139147. http://dx.doi.org/10.1016/j.lwt.2013.09.003.

Sant'Anna, V., F. D. P. Christiano, L. D. F. Marczak, I. C. Tessaro, and R. C. S. Thys. 2014. The effect of the incorporation of grape marc powder in fettuccini pasta properties. LWT Food Sci. Technol. (Campinas) 58:497-501. http://dx.doi.org/10.1016/j. lwt.2014.04.008.

Stratulat, I., M. Britten, S. Salmieri, P. Fustier, D. St-Gelais, C. P. Champagne, and M. Lacroix. 2014. Enrichment of cheese with bioactive lipophilic compounds. J. Funct. Foods 6:48-59. http:// dx.doi.org/10.1016/j.jff.2013.11.023.

Torri, L., M. Piochi, V. Lavelli, and E. Monteleone. 2015. Descriptive sensory analysis and consumers' preference for dietary fibreand polyphenol-enriched tomato purees obtained using winery by-products. LWT Food Sci. Technol. (Campinas) 62:294-300. http://dx.doi.org/10.1016/j.lwt.2014.12.059.

Tseng, A., and Y. Zhao. 2013. Wine grape pomace as antioxidant dietary fibre for enhancing nutritional value and improving storability of yogurt and salad dressing. Food Chem. 138:356-365. http:// dx.doi.org/10.1016/j.foodchem.2012.09.148.

Tyle, P. 1993. Effects of size, shape and hardness of particles in suspension on oral texture and palatability. Acta Physiol. (Amst.) 84:111-118.

Utz, K.-H. 1986. The interocclusal tactile fine sensitivity of the natural teeth as studied by aluminium oxide particles. Dtsch. Zahnarztl. Z. $41: 313-315$.

Verbeke, W. 2006. Functional foods: Consumer willingness to compromise on taste for health? Food Qual. Prefer. 17:126-131. http:// dx.doi.org/10.1016/j.foodqual.2005.03.003.

Verbeke, W., J. Scholderer, and L. Lähteenmäki. 2009. Consumer appeal of nutrition and health claims in three existing product concepts. Appetite 52:684-692. http://dx.doi.org/10.1016/j. appet.2009.03.007.

Vit, P., T. Sancho, A. Pascual, and R. Deliza. 2011. Sensory perception of tropical pot honeys by Spanish consumers, using free choice profile. J. ApiProduct ApiMedical Sci. 3:174-180. http://dx.doi. org/10.3896/IBRA.4.03.4.04.

Wadhwani, R., and D. J. McMahon. 2012. Color of low-fat cheese influences flavor perception and consumer liking. J. Dairy Sci. 95:2336-2346. http://dx.doi.org/10.3168/jds.2011-5142.

Wardle, J., and L. Cooke. 2008. Genetic and environmental determinants of children's food preferences. Br. J. Nutr. 99:S15-S21. http://dx.doi.org/10.1017/S000711450889246X.

Yu, J., and M. Ahmedna. 2013. Functional components of grape pomace: their composition, biological properties and potential applications. Int. J. Food Sci. Technol. 48:221-237. http://dx.doi. org/10.1111/j.1365-2621.2012.03197.x.

Zhu, F., B. Du, L. Zheng, and J. Li. 2015. Advance on the bioactivity and potential applications of dietary fibre from grape pomace. Food Chem. http://dx.doi.org/10.1016/j.foodchem.2014.07.057. 